\title{
O PRINCÍPIO DA CONSENSUALIDADE NO ESTADO DEMOCRÁTICO DE DIREITO - UMA INTRODUÇÃO
}

Cláudio Cairo GonÇalves ${ }^{1}$

1. Introdução - 2. Consenso e sua significação - 3. Democracia e Legitimidade - 4. O surgimento da Consensualidade - 5. Sobre os principios jurídicos - 6. O Princípio da Consensualidade - afirmação de sua existência - 7. Referências Bibliográficas.

\section{Introdução}

A passagem do Estado Totalitário da Idade Média para o Estado Democrático de Direito do século XX, fez com que se implementasse um modelo que acolhe, exige e estimula uma crescente participação dos indivíduos, das comunidades e das organizações civis no envolvimento com as questões de natureza pública, havendo maior espaço para a intervenção popular nas decisões políticas.

É que, em determinado momento histórico, além de formalizar o acesso ao exercício do poder, tornou-se necessário erigir condições para que o seu exercício fosse considerado socialmente legítimo. Buscou-se instituir, portanto, um procedimento que intentasse refletir efetivamente uma vontade coletiva dentro da sociedade. Desta feita, o exercício do poder estaria respaldado na vontade coletiva, i.e., respaldado na legitimidade do sistema político-jurídico.

\section{Consenso e sua significação}

Tal procedimento orientava-se pela busca de algo que representasse a vontade coletiva. Esse "algo" significou justamente um elemento semântico denominado

I O Autor é Mestre em Direito na UFBA, Professor das Faculdades de Direito da UFBA e da UNIME, Procurador da Fazenda Estadual e Advogado. 
"consenso", do latim consensus, que na pragmática da comunicação humana significa consentimento; acordo; opinião geral; anuência" ?

$\mathrm{Na}$ acepção da pragmática jurídica", a palavra "consenso" possui a mesma significação de consentimento, que por sua vez, equivale à expressão "ter o mesmo sentir". No âmbito jurídico, é certo que consenso e consentimento equivalem à idéia de manifestação de vontade, aprovação, outorga.

Nesse sentido, era deveras impossível que um sistema político-jurídico conseguisse refletir, a uma só vez, a vontade de todos individualmente. A empresa constituiu a busca da vontade geral, ainda que não fosse de todos, individualmente. O modelo procedimental que buscou o consenso efetivou-se pela realização da vontade de uma maioria.

Por outro lado, em nível da especialização de funções, tornou-se indispensável que existisse uma determinada classe de pessoas cuja atividade se restringisse especialmente à seara política, ou seja, "quando o governo das comunidades antigas deixa de ser direto - nas quais os cidadãos governavam-se eles próprios - e passa a intermediário", surgem os regimes representativos, em que a idéia de consenso básico dos cidadãos passa a ser o "principal instrumento de le gitimação da atividade politic a" Instituem-se, portanto, os regimes representativos, cuja noção básica se estreitou à de democracia.

\section{Democracia e Legitimidade}

Para José Eduardo FARIA, "democracia é o regime dos sistemas abertos, ou seja, aqueles que procuram garantir a manutenção das regras do jogo, a sobrevivência dos textos constitucionais, a impessoalidade e o rodízio do poder, e a ação dos diferentes grupos sociais, sem a eliminação das partes descontentes e da maneira menos coercitiva possivel" (ob. cit., p. 62).

Convém destacar, que a democracia conseguiu, com a extensão da cidadania às classes mais despossuídas de recursos materiais, implantar o que se pode chamar de plena igualdade formal entre as pessoas do povo, posto que o voto de todos, e o de cada um, tem o mesmo peso, a mesma força perante o sistema político-eleitoral. Isto representa uma conquista histórica, que passou a ser adotada a partir do fim do século XIX, com o sufrágio universal.

O modelo de democracia adotado pelos governos oriundos das revoluções liberais do último quartel do século XVIII, para Manoel Gonçalves FERREIRA FILHO (1990: 72), fez instituir a democracia representativa que significa "um tipo de democracia em que o povo se governa indiretamente, por intermédio de representantes que elege".

2 Segundo Francisco da Silveira Bueno (1963).

3 Cf. De Plácido e Silva (1991).

4 Cf. José Eduardo Faria, 1978, p. 62. 
Ao longo dos acontecimentos históricos, verifica-se, porém, a existência de deformações nos regimes políticos em que se instituiu a democracia representativa. Tais deformações podem ser encontradas em um sistema que se respalda in absoluto na representatividade. É que, no contexto político moderno, a noção de democracia representativa não oferece mais o consenso, pois a integração do povo na vida política tem sido cada vez menos constante, em face de que não mais participa, nem delibera, exceto no dia da eleição. A isto cabe mencionar e acrescentar, como fatores que limitam e investem contra a noção de democracia representativa: o peso e a pressão exercidos pelos vícios eleitorais e partidários; a propaganda dirigida; a falta de informação democrática; a incipiente consciência cívica, pública e opinativa dos cidadãos, sempre sujeita à manipulação pelos poderes e veículos de informação; dúvidas sobre financiamento de campanha; falta de controle social; falta de equilíbrio entre os poderes públicos: preponderância e centralismo político e econômico da União, entre outros 5 .

José Eduardo FARIA, em lúcida observação, afirma que uma faceta importante do processo de recomposição de poder do Estado-nação:

"são as recorrentes discussões sobre o sentido, o alcance, e o 'locus' da democracia representativa no âmbito da economia globalizada; sobre a substituição da política de mercado como fator determinante de "âmbito público"; sobre a erosão dos distintos mecanismos de formaçãa de identidade coletiva forjados pela modernidade; sobre os novos tipos de sociabilidade gerados pela mercantilização das mais diversas relações sociais; sobre o impacto fragmentador ocasionado pela diversidade de ritmos, dinâmicas e horizontes temporais com relação às percepções da história e de um futuro nacional; sobre a efetividade da representação parlamentar; e, por fim, sobre o caráter cada vez mais difuso e menos 'transparente' da elaboração das regras jurídicas em matéria econômica, monetária, financeira, cambial, industrial e comercial" (1999: 28).

Nesse sentido, Edvaldo BRITO ${ }^{6}$ lembra a tese defendida por Raymond ARON, segundo a qual a democracia deve ser considerada como governo de minoria, "por que não pode ser caracterizado como o governo em que o povo decide, dada a complexidade da vida moderna". Desta forma, o Autor referido elenca os aspectos jurídicos que tendem ao aprimoramento da democracia, instituindo-se a "chamada democracia semi-direta", principalmente através dos institutos da iniciativa popular, referendo (referendum), plebiscito (plebiscitum) ${ }^{7}$. Lembra ainda, o recall ou revoca,

5 A esse respeito: Paulo Bonavides, Teoria Constitucional da Denocracia Participativa, 2001, p.25 e segs.; Roberto Amaral, A Democracia Representativa está morta; Viva a Democracia Participativa! 2001, p. 19 e segs.

6 Em seu artigo "Aspectos Jurídicos da Democracia Participativa como uma Revisão do Processo Decisório", 1996: p. 115-131.

7 Dalmo de Abren Dallari, analisando os institutos da democracia semidireta, conceitua referendum, plebiscito, a iniciativa, o veto e o recall. Assim, em linhas gerais. o Autor conceitua os institutos da seguinte forma: O referendum consiste na consulta à opinião pública para a introdução de um emenda constitucional ou mesmo de uma lei ordinária. quando esta afeta um interesse público relevante: O plebiscito consiste numa consulta prévia à opinião popular; A iniciativa confere a um 
que a Constituição brasileira não contempla, embora pudesse ser útil ao nosso sistema de governo presidencialista.

O que se estabeleceu através de consenso é que todo poder emana do povo, que o exerce por meio de representantes eleitos ou diretamente, consagrando em nível constitucional (Parágrafo único, artigo $1^{\circ}$ da C.F. de 1988), como fundamento do Estado, a participação e o reconhecimento do indivíduo como pessoa integrada na sociedade estatal e que todo o funcionamento do Estado estará submetido à vontade popular ${ }^{8}$.

Diogo de Figueiredo MOREIRA NETO destaca o fato de que na democracia clássica. a participação popular está voltada "à escolha dos governantes", enquanto que a democracia emergente do final do século XX, volta-se "à escolha de como se quer ser governado", através de maior participação política (2.000: 41).

O dado elementar dessa conformação é a histórica busca da legitimidade através da participação popular, por meio do aprimoramento doutrinário e legislativo das instituições existentes na sociedade".

Todavia, fica sacramentado que quanto maior a busca e a obtenção do consenso, da participação, e do envolvimento dos indivíduos, dos grupos e das comunidades em torno das ações estatais, maior será o retorno e as vantagens a serem desfrutadas por todos. notadamente, porque este é um reclame presente no atual estágio do Estado Democrático de Direito, estatuído na Lei Suprema. Como consequeencia direta do aprimoramento, instituição e efetivação dos instrumentos democráticos tem-se maior respaldo nas ações do Estado, voltadas para realização precípua de seus fins ${ }^{10}$.

Em nosso trabalho de Mestrado em Direito na UFBa" ${ }^{11}$, concluído em dezembro de 2001, tivemos oportunidade de afirmar que é no campo constitucional que se dá

certo número de eleitores o direito de propor uma emenda constitucional ou um projeto de lei; $\mathrm{O}$ veto popular é um instituto que dá aos eleitores, após a aprovação de um projeto pelo Legislativo, um prazo para que requeiram a aprovação popular; o recall judicial é a possibilidade de que decisões dos juízes e tribunais, exceto a Suprema Corte, negando a aplicação de uma lei, por julgá-la inconstitucional, deveriam poder ser anuladas pelo voto da maioria dos eleitores (1995: 130 e segs.).

8 Cf. José Afonso da Silva. 1996 p. 106.

9 A própria Constituição Federal de 1988, estattui em seu artigo $1^{\circ}$ que a República Federativa do Brasil. formada pela união indissolúvel dos Estados e Municípios e do Distrito Federal, constitui-se em Estado Democrático de Direito e tem como fundamentos. entre outros o pluralismo político, sendo que infirma a participação popular ao preceituar que todo o poder emana do povo, que o exerce por meio de representantes eleitos ou diretamente. nos termos da Constituição.

10 Corroborando o entendimento de que os fins do Estado também se realizam com o Dircito veja-se, sobre as conexões existentes entre Direito e Estado, Nelson Saldanha, que considera Estado, como sendo "um meio, em face dos "fins" (ou de valores) que são entretanto fins do direito: na verdade valores que correspondem à própria ordem jurídico-politica. em face dos quais se interpretam as açöes estatais e as situaçôes jurídicas".(ob. cit., 37).

11 O Contrato Administrativo em face da atual concepção de Estado. Salvador: 2001, Iv., p. 192. Dissertação de Mestrado. UNIVERSIDADE FEDERAL DA BAHIA - DIREITO. Orientador: Edvaldo Pereira de Brito. Biblioteca Depositária: BIBLIOTECA CENTRAL E FACULDADE DE DIREITO DA UFBA, cujo enunciado é: Estudo da atual concepção jurídica de Estado, que se volta para o aprimoramento de institutos e figuras contratuais celebrados pela Administração Pública. 
o embate das forças reais de poder ${ }^{12}$, pois que aqui se insere a questão da análise da legitimidade da concepção juridica do Estado, que se tenha e que se queira, uma vez que a organização estatal, juridicamente estruturada através de um arcabouço de competências e limitações, deve refletir o anseio colhido na sociedade, ou que pelo menos esteja implícita a idéia de "consenso", compreendendo as formas de participação popular, baseadas não somente no sistema representativo, mas decididas ou referendadas também pelo 'todo' social.

\section{O surgimento da Consensualidade}

Nesse campo da legitimidade do Estado, no espaço normativo e de execução de políticas públicas, é que surge a consensualidade, trazida, v.g., por Diogo de Figueiredo MOREIRA NETO no seu Mutações, em que vigora o refluxo da imperatividade dos atos administrativos, dando espaço para instrumentos de coordenação operativa entre sociedade e Estado (2.000: 41).

A consensualidade, de acordo com o Autor, pode ser percebida a partir das funções fundamentais do Estado. "Primo, a consensualidade na produção das normas, como o reaparecimento de fontes alternativas, fontes consensuais e de fontes extra-estatais: a regulática. Segundo, a consensualidade na administração dos interesses públicos, como o emprego das formas alternativas consensuais de coordenação de ações, por cooperação e por colaboração. Tertio, a consensualidade na solução dos conflitos, com a adoção de formas alternativas de composição" (loc. cit.).

Para Diogo de Figueiredo MOREIRA NETO, "a participação e a consensualidade tornaram-se decisivas para as democracias contemporâneas, pois contribuem para aprimorar a governabilidade (eficiência); propiciam mais freios contra o abuso (legalidade); garantem a atenção de todos os interesses (justiça); proporcionam decisão mais sábia e prudente (legitimidade); desenvolvem a responsabilidade das pessoas (civismo); e tornam os comandos estatais mais aceitáveis e facilmente obedecidos (ordem)" (2.000, p. 41$)$.

Odete MEDAUAR, em seu Direito Administrativo em evolução, analisando a aplicação da clássica doutrina do contrato administrativo, desvinculada da tradicional feição privatística, com a presença das cláusulas exorbitantes e da desigualdade entre as partes contratantes, aponta para as recentes preocupações surgidas já na década de setenta, no sentido de minorar a desigualdade contratual e a unilateralidade dos atos administrativos, podendo-se se falar em Administração concertada. Tais preo-

12 Idéia veiculada no livro de Ferdinand LASSALE, A Essência da Constituição, segundo a qual a Constituição é o resultado do embate das forças reais de poder existentes na sociedade. O Autor alemão, afirma que a lei fundamental (Constituição) é uma "força ativa que faz, por uma exigência da necessidade, que todas as outras leis e instituições jurídicas vigentes no país sejam o que realmente são" e, sendo assim, esta força ativa constitui os "fatores reais de poder", que regem a sociedade. Elencando os fatores reais de poder de sua época, menciona a monarquia; a aristocracia; a grande burguesia; os banqueiros; a pequena burguesia e a classe operária (1998: 26 e segs.). 
cupações vêm a reforçar a tese da consensualidade, motivada pela: "afirmação pluralista, a heterogeneidade de interesses detectados numa sociedade complexa; $a$ maior proximidade entre Estado e sociedade, portanto entre Administração e sociedade" (1992: pp. 198 usque 201).

Baseada nestas idéias, Medauar traz o pensamento de Paul AMSELEK, que aponta para o desenvolvimento, na atualidade, ao lado dos mecanismos democráticos clássicos, de "formas mais autênticas de direção juridica autônoma das condutas", que abrangem, de um lado, a conduta do poder público no sentido de debater e negociar periodicamente com interessados as medidas ou reformas que pretende adotar, de outro, o interesse dos indivíduos em particular, individualmente ou em grupos, na tomada de decisões da autoridade administrativa, seja sob a forma de atuação em conselhos, comissões, grupos de trabalhos no interior dos órgãos públicos, seja sob a forma de múltiplos acordos celebrados. E afirma ainda que, conforme Rosario FERRARA, associa-se a esse processo: o florescimento de módulos contratuais à crise da lei formal como ordenadora de interesses, em virtude de que esta passa a enunciar os objetivos da ação administrativa e os interesses protegidos; $o$ processo de "deregulation": a emersão de interesse metaindividuais; a exigência de racionalidade, modernização e simplificação da atividade administrativa, assim como maior eficiência e produtividade, alcançados de modo mais fácil quando há consenso sobre o teor das decisões.

No campo da atuação da Administração Pública já se pode vislumbrar, no ordenamento jurídico brasileiro, normas que prevêm mais amplamente a chamada consensualidade entre a Administração Pública e os administrados, seja através de novas figuras contratuais ou de sistemas de transferência do exercício de certas atividades a cargo do ente estatal para entes da sociedade, regidas predominantemente sob o regime de direito privado, tais como a termos de parceria, franquia, terceirização, a prestação de serviços mediante cooperativas prestadoras de serviços públicos, bem assim através da gestão associada dos entes federados através de convênios e consórcios, tudo na negociação aberta do interesse público.

Depreende-se um intenso incentivo à cooperação e colaboração com o setor público. Frise-se que a participação, e o envolvimento dos indivíduos e das comunidades depende principalmente de sua conscientização para atuação na esfera pública, e diretamente de sua organização, como pessoas físicas ou jurídicas, nacionais ou estrangeiras, que, constituídas com objetivos específicos, passam a travar relações diretas com a Administração Pública, na forma de prestadora de serviços públicos, sob a forma de concessão, permissão, ou, na forma de prestadora de serviços de interesse geral, através dos contratos de gestão, ou ainda, a realizar uma espécie de monitoramento das ações do Poder Público e das atividades desempenhadas pelos prestadores de serviços públicos mediante concessão, permissão, ou gestão, atuando no interesse da fiscalização e controle das atividades postas à disposição dos usuários, exercendo, com plenitude, altivez, autonomia e independência a tarefa de defender os direitos constitucionais dos usuários de serviços públicos, na forma do artigo 175 da Lei Maior.

Tal organização deve ser incentivada pelo Poder Público, na estruturação de entidades voltadas para o exercício de atividades do chamado "terceiro setor", 
entidades de interesse geral não estatais, como forma de incrementar a prestação, a fiscalização e o controle de atividades delegadas de poder público, atividades estas de mais alto interesse público, atuando no auxílio do próprio Estado, e no interesse da coletividade em geral. O Poder Público deve agir na esteira de propiciar os meios necessários a que os usuários e a população em geral possam exercitar a participação, seja na colaboração, seja na fiscalização.

Assim também, ao Estado deve estar ungida a realização das funções decorrentes da incumbência constitucional que the é dirigida, sempre voltado para a persecução do interesse público e geral. Acorre atualmente o fato de que a sociedade, através de suas entidades organizadas, passa a ter um papel fundamental também na verificação do cumprimento do programa constitucional, tanto na persecução do interesse público, através da atuação participativa, que pode ser dividida em atuação participativa direta (exercício de função delegada de Poder público) e atuação participativa indireta (fiscalização), quanto na persecução do interesse geral, em prol de toda coletividade, também prevista no programa jurídico-legal ${ }^{13}$.

Quanto à prestação da tutela jurisdicional, formas alternativas de resolução de conflitos têm sido introduzidas na legislação processual, e que também remontam e denotam a busca do consenso, por meio da orientação jurídico-processual para a preponderância na utilização de institutos capazes de oferecer maior celeridade na resolução dos litígios, tal como o da transação, introduzido na Lei dos Juizados Especiais (Lei $n^{\circ} 9.099 / 95$ ) como objetivo a ser sempre alcançado (artigo $2^{\circ}$ ) e que, na esfera penal, passou a ser possível como hipótese de suspensão do processo, para os crimes com menor potencial ofensivo. Na esfera cível, a transação foi introduzida no Título VI - Das Várias Espécies de Contrato, Capítulo XIX, da nova Lei $\mathrm{n}^{\circ} 10.406 / 02$, que institui o novo Código Civil, ainda em prazo de vacância, merecendo, pois, um tratamento de natureza contratual.

Ademais, com novas previsões normativas, em sede do processo civil, como no caso da arbitragem (Lei $\mathrm{n}^{\circ} 9.307 / 96$ ), em que as pessoas capazes de contratar poderão valer-se da arbitragem para dirimir litígios relativos a direitos patrimoniais disponíveis, inclusive de modo a atrair a vinda para o Brasil de novos capitais e investimentos estrangeiros, assim também, como o que ocorreu com a introdução do princípio da conciliabilidade $^{14}$ através da obrigatoriedade de comparecimento das partes para audiência preliminar e de conciliação, em que os sujeitos processuais comparecem para a tentativa de conciliação através da transação, como forma de autocomposição dos litígios (Lei $\mathrm{n}^{\circ}$ 8.952/94), instituiu-se uma tendência às alternativas viáveis à solução dos litígios.

13 O prof. Luís Roberto Barroso anota e encarece a fiscalização participativa como poderoso instrumento para a exigência do cumprimento da Constituição e das leis ( $O$ Direito Constitucional e a efetividade de suas normas. Rio de Janeiro: Renovar, 2002, $6^{\mathbf{a}}$ edição atualizada, p. 131).

14 Luiz Rodrigues Wambier, Flávio Renato Correra de Almeida e Eduardo Talamini afirmam que a "tentativa de conciliação, como verdadeira meta a ser perseguida, em apoio à idéia de otimização dos serviços do Poder Judiciário, foi elevada a dever do magistrado" (2002; 591). 
Não de outra forma, as circunstâncias relativas à introdução pelo Congresso Nacional quanto à disposição e regulamentação dos incisos I, II e III do artigo 14 da Constituição Federal, através da Lei $n^{\circ} 9.709 / 98^{15}$, no que concerne ao plebiscito, ao referendo e à iniciativa popular, também repercute de forma decisiva no aprimoramento das formas de obtenção do consenso.

\section{Sobre os princípios jurídicos}

Com relação à categoria jurídica dos princípios, apesar da variabilidade de respostas e critérios que se possa obter para uma definição do que seja "princípio jurídico" e sua distinção em relação à categoria da "regra jurídica", convém afirmar que as normas jurídicas, modernamente, são veiculadas através de regras e de princípios ${ }^{16}$.

Cabe analisar, após o reconhecimento da força normativa dos princípios, o modo pelo qual ocorre o desvelamento do seu conteúdo normativo, inclusive através da variação do seu grau de abstração e generalidade, atentando-se aos seus fundamentos de validade, bem como aos critérios de resolução do choque de normas, através de mecanismos propostos para sua dilucidação, tal como na moderna doutrina da ponderação de bens, referida por Karl LARENZ, como meio à serviço da determinação do alcance dos direitos fundamentais ou princípios constitucionais que colidam entre si no caso concreto ${ }^{17}$ (regras $x$ regras/principios $x$ princípios).

\section{O Princípio da Consensualidade - afirmação de sua existência}

Desta forma, afirmando sua existência, pretende-se verificar as bases jurídicas, explícitas ou implícitas, da consensualidade, na qualidade de princípio jurídico, de tal maneira que, mediante sua afirmação no ordenamento jurídico, possa firmar-se

15 No seu artigo $2^{\circ}$ estabelece que plebiscito e referendo são consultas populares formuladas ao povo para que delibere sobre matéria de acentuada relevância, de natureza constitucional, legislativa ou administrativa. Consoante seu parágrafo primeiro, plebiscito é convocado com anterioridade a ato legislativo ou administrativo, cabendo ao povo, pelo voto, aprovar ou denegar o que lhe tenha sido submetido, enquanto que, na forma do parágrafo segundo, referendo é convocado com posterioridade a ato legislativo ou administrativo, cumprindo ao povo a respectiva ratificação ou rejeição. Com relação à iniciativa popular, prevê o artigo 13 da lei, que esta consiste na apresentação de projeto de lei à Câmara dos Deputados, subscrito, por, no mínimo, um por cento do eleitorado nacional, distribuído pelo menos por cinco estados, com não menos de três décimos por cento dos eleitores de cada um deles.

$16 \mathrm{Na}$ acepção de Paulo de Barros CARVALHO, de uma maneira geral, "os princípios aparecem como linhas diretivas que iluminam a compreensão de setores normativos, imprimindo-lhes caráter de unidade relativa e servindo de fator de agregação num dado feixe de normas" (Curso de Direito Tributário. São Paulo: Editora Saraiva, 1999, $11^{\text { }}$ edição revista, p. 106).

17 LARENZ, Karl. Metodologia da Ciência do Direito, 1997, p. 575. 
o refluxo da imperatividade e a tendência reequilibradora da afirmação imemorial da coerção, sendo percebido, a partir das funçōes estatais fundamentais, como a possibilidade de dotar a Administração Pública, atuante na vigência do Estado Democrático de Direito, de profissionalidade (ou responsividade ${ }^{18}$ ) na execução de suas atribuições, de forma eficiente e econômica, em prol de toda coletividade.

Nesta conformidade, este trabalho constitui-se numa introdução ao tema, com vistas a demonstrar a necessidade da análise da consensualidade, na qualidade de princípio jurídico, em pleno vigor do Estado Democrático de Direito, justificando-se pela inovação, originalidade e oportunidade da abordagem, vindo a constituir em importante contribuição ao conhecimento científico sobre a matéria no Direito, sendo certo que diversas indagações acorrem, destacando-se as questões de saber-se se a consensualidade é verdadeiramente um princípio jurídico do Estado Democrático, e que posição ocupa no ordenamento jurídico, a partir da análise da Constituição Federal de 1988(?). Não sendo princípio constitucional, estaria no campo dos princípios gerais do direito? E quanto ao seu caráter normativo, que tipo de comando normativo se lhe justifica (impositivo (positivo ou negativo), proibitivo, autorizativo ou indicativo)? Tais indagações ficam para as novas incursões no tema.

\section{Referências Bibliográficas}

Amaral, Roberto. A Democracia Representativa está morta; Viva a Democracia Participativa! In: Direito Constitucional - Estudos em homenagem a Paulo Bonavides. São Paulo: Malheiros, 2001, p. 19 e segs.

ASSOCIAÇÃO BRASILEIRA DE NORMAS TÉCNICAS. nbr6023: Informação e Documentação - Referências - Elaboração. Rio de Janeiro, 2.000.

Barroso Luís Roberto. O Direito Constitucional e a efetividade de suas normas. Rio de Janeiro: Renovar, 2002, $6^{\text {a }}$ edição atualizada.

BONAVIDES, Paulo. Teoria Constitucional da Democracia Participativa. São Paulo: Malheiros, 2001.

BRASIL. Legislação Federal. Brasilia: Senado Federal, "http://www.senado.gov.br", acessado em 20/08/02.

BRITO, Edvaldo. Aspectos Jurídicos da Democracia Participativa como uma Revisão do Processo Decisório. Revista da Faculdade de Direito da UFBa, Salvador: [s.n.], 1996, XXXVI v., nº 50, p. 115-131.

18 Ampara este entendimento, a afirmação feita por Diogo de Figueiredo Moreira Neto (Considerações sobre a Lei de Responsabilidade Fiscal, 2001, p. 60), quando averba que no "Estado Democrático de Direito se inova o princípio da responsividade, introduzindo um novo dever substantivo, em razão do qual o administrador público também fica obrigado a prestar contas à sociedade pela legitimidade de seus atos". O próprio Diogo de Figueiredo Moreira Neto encaminha seu pensamento no sentido de extrair a existência da responsividade como princípio jurídico quando enuncia que a responsividade é "a obrigação de o administrador público responder pela violação da legitimidade, ou seja. pela postergação ou deformação administrativa da vontade geral, que foi regularmente expressa, explícita ou implicitamente, na ordem jurídica". 
BUENO, Francisco da Silveira (Org.). Dicionário Escolar do Professor. Brasília: Ministério da Educação e Cultura, 1963.

Carvalho, Paulo de Barros. Curso de Direito Tributário. São Paulo: Editora Saraiva, 1999, $11^{a}$ edição, revista.

Dallari. Dalmo de Abreu. Elementos de Teoria Geral do Estado. São Paulo: Saraiva, 1995.

FARIA, José Eduardo. Poder e Legitimidade. São Paulo-SP, Editora Perspectiva, 1978.

O Direito na Economia Globalizada. São Paulo-SP: Malheiros Editores, 1999.

FERREIRA FILHO, Manoel Gonçalves. Curso de Direito Constitucional. São Paulo: Editora Saraiva, 1990, $18^{a}$ edição, rev. e atual..

GONÇALVES, Cláudio Cairo. O Contrato Administrativo em face da atual concepçăo de Estado. Salvador: Dissertação de Mestrado. UNIVERSIDADE FEDERAL DA BAHIA - DIREITO. Orientador: Edvaldo Pereira de Brito. Biblioteca Depositária: BIBLIOTECA CENTRAL E FACULDADE DE DIREITO DA UFBA, 2001, 1v., 192p..

GUSTIN, Miracy Barbosa de Sousa; Dias, Maria Tereza Fonseca. (Re)Pensando a Pesquisa Jurídica. Belo Horizonte: Del Rey Editora, 2002.

Larenz, Karl, Metodologia da Ciência do Direito. Lisboa: Fundação Calouste Gulbenkian, 1997, $3^{\text {a }}$ edição.

LASSALLE, Ferdinand. A Essência da Constituição. Rio de Janeiro - RJ: Lumen Juris, 1998, $4^{a}$ edição.

MEDAUAR, Odete. O Direito Administrativo em evolução. São Paulo: Editora Revista dos Tribunais, 1992.

MOREIRA NETO, Diogo de Figueiredo. Mutações do Direito Administrativo. Rio de Janeiro: Renovar, 2.000.

. Considerações sobre a Lei de Responsabilidade Fiscal. Rio de Janeiro: Renovar, 2001.

SALDANHA, Nelson. O Poder Constituinte. São Paulo-SP: Editora Revista dos Tribunais, 1986, Reedição.

SILVA, José Afonso da. Curso de Direito Constitucional Positivo, São Paulo, Malheiros Editores, 1996, $11^{a}$ edição rev..

SILVA, De Plácido e. Vocabulário Jurídico. Rio de Janeiro: Editora Forense, 1991, $3^{a}$ edição universitária.

Wambier, Luiz Rodrigues; Almeida, Flávio Renato Correra de; Talamini, Eduardo. Curso Avançado de Processo Civil. São Paulo: Editora Revista dos Tribunais, $2002,4^{a}$ edição, revista, atualizada e ampliada. 